\title{
Perinatal exposure to diethylhexyl phthalate induced polycystic ovarian syndrome-like changes in F1 offspring mice
}

\author{
Ki Hyon Kil, M.D, Ph.D
}

Department of Obstetrics and Gynecology, St. Peter's hospital, Seoul, Republic of Korea

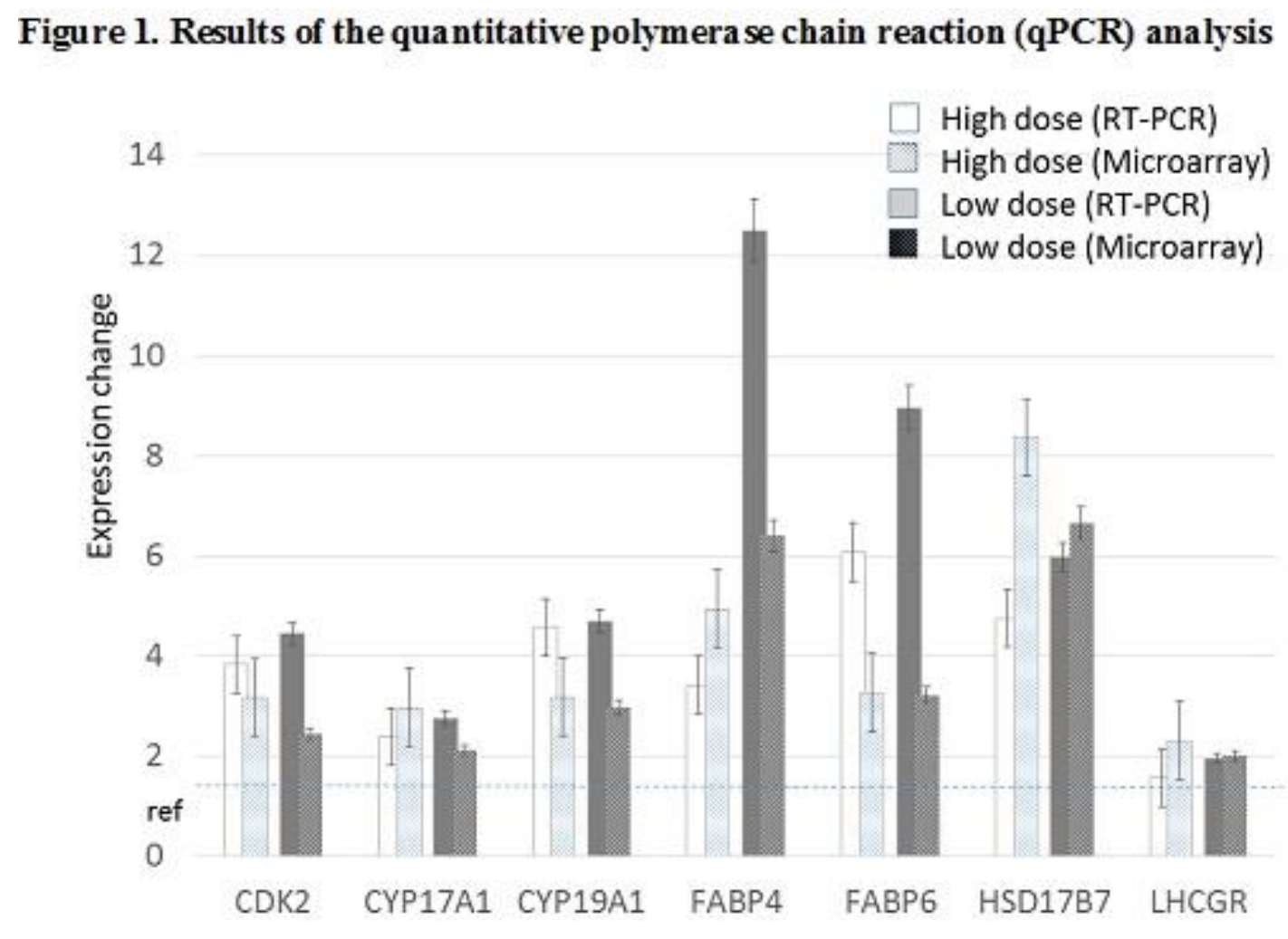

Comparison of microarray analysis and quantitative real-time PCR data for gene expression altered by perinatal DEHP.
Figure 2. Results of the micro-CT an alysis in F1 mice subjected to perin atal DEHP exposure.

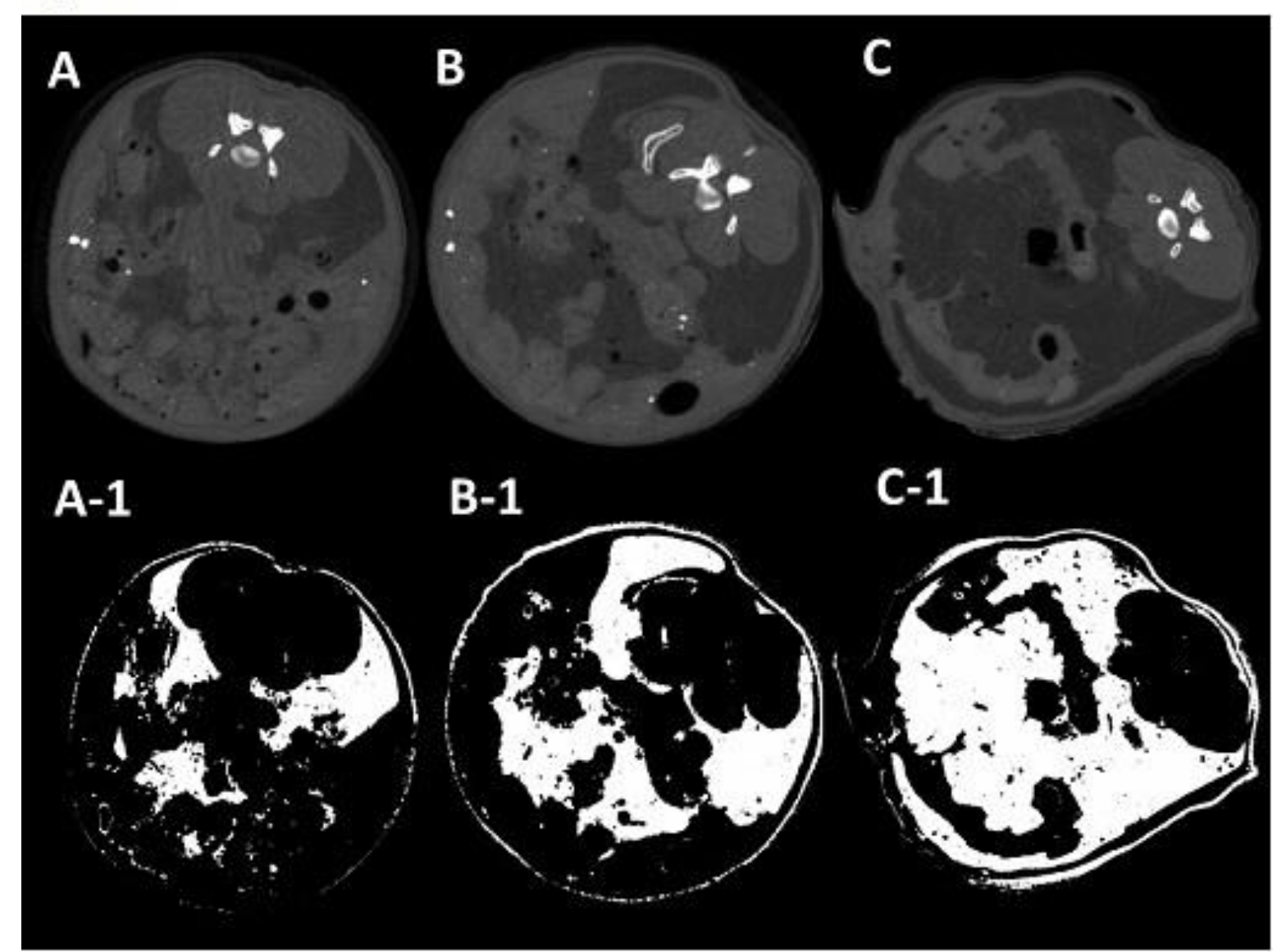

The images in upper panel are computed-tomography images while those in the lower panel are selected images of visceral fat. The white areas in the lower-panel images represent fat tissue, and the black areas represent other tissues of the viscera. A and A-1 indicate control mice, B and B-1 indicate low-dose treatment mice, and C and C-1 indicate high-dose treatment mice. Mice from the low-dose and high-dose treatment groups exhibited significantly more visceral fat than the control mice.

\section{Purpose :}

Polycystic ovarian syndrome (PCOS) is the most common endocrinopathy in infertile women, and affects approximately $5-15 \%$ of reproductive age women. We demonstrated that exposure of mice to DEHP via the parenteral route resulted in altered gene expression in siblings and induced pathophysiologic changes similar to those observed in PCOS women.

\section{Methods:}

Adult female CD-1 [Crl:CD-1 (ICR) BR] mice were obtained and bred with male mice of the same strain at the breeding facility. Three pregnant mice were injected subcutaneously with corn oil (control group, $n=1$ ) or DEHP (Sigma-Aldrich, Inc., St. Louis, MO) dissolved in corn oil during pregnancy (gestation days 9-16) and lactation (postpartum days 7-21). Both ovaries were removed from $\mathrm{F} 1$ female mice per group (control group, $n=5$; low dose group, $n=6$; high dose group, $n=8$ ), and RNA was extracted from three ovaries of different mice in each group. Total RNA was extracted from three ovaries of different mice in each group using TRIzol Reagent ${ }^{\circ}(\mathrm{OH}, \mathrm{USA})$ according to the manufacturer's instructions. Real-time quantitative PCR was performed in triplicates in 384-well plates.

\section{Results:}

The microarray analysis indicated that 529 genes were significantly dysregulated after low-dose perinatal exposure, while 617 genes showed significant changes after high-dose perinatal exposure to DEHP. Ninetyfive genes were commonly upregulated, and an additional 95 genes were downregulated in both treatment groups. The RT-PCR data corroborated the results of the microarray analysis. The mean body weight of the control group (34.7 $\pm 1.47 \mathrm{~g}, \mathrm{n}=5$ ) was significantly lower (paired t-test, $P<0.05$ ) than those of the low-dose $(41.92 \pm 4.73 \mathrm{~g}, \mathrm{n}=6)$ and high-dose treatment groups $(42.8 \pm 2.26 \mathrm{~g}, \mathrm{n}=8)$. The amount of visceral fat was significantly lower in the control group $(1046.0 \pm 318.8 \mathrm{~mm} 3)$ than in the treatment groups (low-dose group, $2442.5 \pm 583.3 \mathrm{~mm} 3$; high-dose group, $2496.05 \pm 987.5 \mathrm{~mm} 3)$. The percentage of ovarian area exhibiting hyperthecosis area was higher in the low-dose treatment group $(66.65 \%$, calculated using the equation, hyperthecosis area/total area $\times 100)$ than in the other groups $(40.81 \%$ in the control group, $50.47 \%$ in the high-dose treatment group)

\section{Conclusion:}

Our results suggest DEHP, and not only its metabolite, is toxic enough to affect follicular development. Altogether, these results suggest that perinatal exposure to endocrine-disrupting chemicals might be a candidate factor for the emergence of PCOS in adulthood.

Key Words: DEHP; perinatal period; PCOS; microarray 